\title{
DEATH ITSELF - STUDENTS' PERSPECTIVE OF AZAD JAMMU \& KASHMIR MEDICAL COLLEGE
}

\author{
Shamaila Manzoor, Atiq-Ur-Rehman*, Ziyad Kayani, Ayesha Younas*, Rafia Minhas*** \\ Azad Jammu \& Kashmir Medical College Muzaffarabad Pakistan, *Armed Forces Institute of Radiology \& Imaging/ National University of Medical Sciences \\ (NUMS) Rawalpindi Pakistan, **Wah Medical College, Wah Cantt/National University of Medical Sciences (NUMS) Pakistan, ${ }^{* * *}$ Avicenna Medical College \\ Lahore Pakistan
}

\begin{abstract}
Objective: To outline a frame-work which would help to regulate the emotions of under graduate students, on the death of their patient.

Study Design: An exploratory qualitative study.

Place and Duration of Study: Azad Jammu \& Kashmir Medical College (AJKMC), from Nov 2019 to Dec 2019.

Methodology: Purposive sampling was done from the final year medical students and focus group discussions were carried out for data collection. Twenty five students shared their feelings at the death of first patient under their care. As a whole, $92 \%$ of volunteers experienced the death of their first patients in medical settings. Subsequently, four main themes have been emerged after data analysis. Including; unexpected death, crisis, anticipated death \& resolution.

Results: Inadequate preparation of medical scholars to handle this tragic incidence leads to anxiety, anger, guilt and sense of helplessness. These undesirable sentiments would seriously affect their performance in future. So, they must be handled wisely and professionally.

Conclusion: Consequently, a curricular model emerged as a result of this study recommending following steps. There should be regular debriefing sessions of students from their supervisors and reflective journaling practice of students, as a part of curriculum. Likewise, faculty training for 'end of life theme' would help their students to become more valuable for ailing community.
\end{abstract}

ABSTRACT

Keywords: Curriculum, Death, Students.

This is an Open Access article distributed under the terms of the Creative Commons Attribution License (http://creativecommons.org/licenses/by/4.0), which permits unrestricted use, distribution, and reproduction in any medium, provided the original work is properly cited.

\section{INTRODUCTION}

Death is an essential part of human life; hence, death and medical profession are inseparable. The complex course of death and dying encompasses palliative care, diagnosis and certification of death, performances of last rites and support to the relatives. Nevertheless, the training in caring for dying patient and dealing with patient death is extremely mutable and highly understated ${ }^{1}$. On the contrary, medical schools are often focused on the overwhelming aspect of cure and return to health. However, very little attention is paid to the death in all this business. In reality, we do not want to focus on this aspect of medicine as it detract from the mission in hand...... It is important to emphasize that we can best serve the dying patient and his family by sufficiently addressing this aspect in curriculum ${ }^{2}$. While, sometime this process takes a little longer, so the emotional health of all, including family and caregiver must be prioritized.

Literature has revealed that patient's death has a strong emotional impact on health care provider, irrespective of their level of expertise. Studies have shown

Correspondence: Dr Shamaila Manzoor, D-142, Street-17, UCHS Muzaffarabad AJK Pakistan

Received: 17 Oct 2020; revised received: 05 Dec 2020; accepted: 21 Dec 2020 that students may suffer, "ethical erosion" because they were unprepared for end of life care. Students seem worried and uncertain about this situation. Consequently, this leads to an "informal curriculum" learnt by residents and their senior colleagues ${ }^{3}$. Therefore, it is imperative that this grief should be identified, acknowledged and accepted in the medical profession. So, the applicable sustenance mechanism should be developed, so the health professionals do not suffer the serious adverse effects of compounded and unaddressed grief 4 .

Nevertheless, in civilized world medical education is more than basic sciences and clinical clerkship. They teach the apprentices that how to deal with highly charged emotional challenges? As, how to handle the impact of witnessing the dying process or breaking bad news to family is very important in medical education ${ }^{5}$.

Research is required that how the death of first patient could influence the student. Whether this response could be modelled to up-coming doctor's generation \& incorporate this aspect of medicine in curriculum? Since, very little medical curriculum states that how students should behave, manage their emotions and confront their own grieving process when patient 
dies. This study would help novices, clinicians, teachers and policy makers to prepare future health force for 'end of life theme' by appropriately revising the curriculum.

Whereas, to deal with this challenging aspect of medicine, prevailing medical curriculum is not sufficient. Patient death and dying would be traumatic and stressful time, not only for novel medical scholar but also for knowledgeable physician ${ }^{6}$. Under-graduate medical curricula do not prepare medical scholars for the end of life situations and experiences. The lack of preparation of patient's death engender feeling of grief, apprehension and helplessness in novices ${ }^{7}$. The objectives of this research were, to explore the impact of death of first patient, on final year medical students of Azad Jammu \& Kashmir medical college \& to propose educational strategies, to help prepare students to cope with emotional impact of their first patient's death. So, the research question was, that, what is the impact on medical student, due to death of the first patient under their care?

\section{METHODOLOGY}

The study design was qualitative exploratory ${ }^{8}$. The study was conducted with permission of 'ethics review board' of AJKMC, in meeting held on $14^{\text {th }}$ October 2019. This study was carried out during November 2019 to December 2019 at, Azad Jammu and Kashmir Medical College (AJKMC), Muzaffarabad, affiliated with University of health sciences.

\section{Participant Selection Strategy}

Purposive sampling was done for candidates and selection of site was done, accordingly ${ }^{9}$. Twenty-five students from the final year class (2019) were selected.

Table-I: Demography of participants.

\begin{tabular}{l|c|c}
\hline & $\begin{array}{c}\text { Number of } \\
\text { Participants }\end{array}$ & Percentage \\
\hline Total volunteers & 25 & $100 \%$ \\
\hline Male & 10 & $40 \%$ \\
\hline Female & 15 & $60 \%$ \\
\hline $\begin{array}{l}\text { Known anyone who died } \\
\text { prior to their medical life? }\end{array}$ & 18 & $72 \%$ of $100 \%$ \\
\hline Relatives & 13 out of 18 & $72.7 \%$ of $72 \%$ \\
\hline Friends & 5 out of 18 & $27 \%$ of $72 \%$ \\
\hline $\begin{array}{l}\text { Witnessed death of } \\
\text { person }\end{array}$ & 25 & $100 \%$ \\
\hline In medical setting & 23 & $92 \%$ \\
\hline Family member & 0 & $0 \%$ \\
\hline Accident & 2 & $8 \%$ \\
\hline Age (years) of participants & Mean (SD) : & Range : $24-30$ \\
\hline
\end{tabular}

Inclusion criteria were the students' who have witnessed the death of patients under their care'. Whereas, 'the students who were not involved in the care of critically ill patients were excluded'. Confidentiality and anonymity of the participants were assured and consent was obtained.

\section{Data Collection Strategy}

Four focus group discussions (FGD) were arranged (to avoid large group size) for the collection of data. Therefore, each group comprised of 6 participants. During each focus group discussion following prompts were offered to the students ${ }^{10}$. "How did you feel when first patient died under your care"? "How you have integrated this experience in to your professional life"? "How the seniors and peers around you helped you to acknowledge this experience"? This open-ended strategy was adopted to elicit the medical students' expression without influencing their experiences. Focus group discussions were audiotaped and transcribed verbatim.

\section{RESULTS}

Thematic analysis was deemed most appropriate for this study ${ }^{11}$. This was followed by pattern recognition to discover core themes in this study. Data analysis was proceeded in three stages of coding; open (raw data was systematically analyzed and categorized), axial (construct linkage between data) and selective coding (explanation of phenomenon).

In open coding analysis, twenty categories were established. According to table-II: themes \& sub-themes, in pre-clinical scenario the death was unexpected and promoted feeling of guilt and lack of power where appropriate debriefing was not available. On contrary,

Table-II: Themes \& Sub-themes.

\begin{tabular}{c|l|l}
\hline S No. & Themes & Sub-themes \\
\hline 1. & $\begin{array}{l}\text { Unexpected } \\
\text { death }\end{array}$ & Emotional turmoil, Guilt \\
\hline 2. & Crisis & Negligence, helplessness \\
\hline 3. & $\begin{array}{l}\text { Anticipated } \\
\text { death }\end{array}$ & $\begin{array}{l}\text { Rationalization, Learning } \\
\text { experience }\end{array}$ \\
\hline 4. & Resolution & $\begin{array}{l}\text { Reflection, Behaving } \\
\text { professionally, getting feed-back }\end{array}$ \\
\hline
\end{tabular}

the deaths in clinical scenarios promoted the feelings of sadness, shock and indifference. Which has strengthened the attitude that it has happened due to negligence of colleagues, relaxed rules and regulations and not due to one's fault. This situation was handled by using various coping mechanisms and guided the student professionally, for future. Next, during axial cod- 
ing six overarching themes emerged; comprising preparation, the death event, feelings, the clinical clerk's role, differential factors between deaths and closure.

Lastly, these themes were integrated on the basis of sequence of events occurring. This comprised of four themes (unexpected death (young), the crisis, anticipated death (old, debilitated) \& resolution.

\section{Theme: Unexpected Death}

When student encounter death in reality (the unexpected death); they narrate these death stories with great emotional tone andguilt. The majority of students experienced sadness, frustration, guilt, selfdoubt, blame, helplessness and sense of failure. One of the participant expressed her feelings as,........' the death of that young lady was due to negligence of all of us.... The consultant, the supervisor, the trainee doctors, paramedical staff was responsible for this tragic event. Nobody satisfied me and I remained in guilt for long'..... Another emergency resident narrated that.......' the young boy was dyspneic after a blunt trauma to chest and struggling hard for life, I did chest intubation but he remained in same situation..... then quickly deteriorated and passed away. I blamed myself for his death as I could save him by doing cardiocentesis. But nobody helped me to come out of that guilt. I reassured myself in several months'...... Another participant narrated, 'the event' of an unexpected death as... 'I have watched surgery of this unfortunate patient, and later followed him up in the ward. He was doing well, when suddenly a nurse rushed saying..... Cardiac arrest! So all my team and consultant ran in and the consultant started ordering and the team done CPR' ....... 'The wife of the patient was with him. Suddenly, she was screaming his name. It was so terrible. I was imagining that what would she feeling'...... Similarly, some deaths turned to be learning experiences, which help to offset the experience of a loss of control........ 'I talked to my senior colleague and an experienced nurse a little bit. Whether it was a pulmonary embolism or massive myocardial infarction..... I tried to reflect over past few days' ........

\section{Theme: Crisis}

Death (crisis), causes great feeling of helplessness; For instance, the death of a young patient was depicted by a student as.......' I was working in ICU at that time when I received a call that a four years old child is hit by a car, while playing on roadside. He was dead on arrival and hooked up with a ventilator, I still remember every minute of it. I had never witnessed anyone dying first hand, and this was small four year old kid. I still remember small pen marks and smiley faces on his hands'........ I was guilty and thought about how I would feel in this situation, my nephews and nieces..... How quickly lives could change' ........

\section{Theme: Anticipated Death}

Nevertheless, "anticipated deaths" were frequently experienced as routine as to be dehumanizing. Student's response was universal for naturalness of elderly patient's death, especially with chronic and debilitated patient. While this situation was dealt with coping strategies of rationalization... 'as I was with him, so it affected me so much that I left the room. I wanted to be somewhere quiet'...... ' $\mathrm{hmm}$, it recalled me my grandpa death couple of months ago; I was not around at the time of his death. So, I have kind of learnt that how would it felt if I was present with my grandpa at that time'.......

\section{Theme: Resolution}

Nevertheless, in the resolution, though young death seems tragic yet it provides a chance to students to plan their life principles. .......'I was trying to keep myself calm, I started behaving professionally. We have to work for saving his life, to ensure a patent airway and selection of appropriate drugs'....... However, understanding and rationalization was more dominantly seen in male students. The lesson learned is dependent upon timely feed-back and the integration of various contextual factors which together helped or hindered students' learning. Debriefing session with colleagues and supervisor is vital, to clarify professional ambiguities.

\section{DISCUSSION}

This study proposes that how medical students experiences and interpret their feelings about the death of first patient under their care. This study suggested that $99 \%$ participants perceived emotional impact on patient's death. Patient death strongly shakes the emotions of the medical students even, when they were not close to the patient. Similar, finding has been reported by Hedy S. Wald in 2010, in a study done at Warren Alpert medical school. It stated, that first encounter with death of patients would be imprinted on the minds of students ${ }^{12}$. Nevertheless, no time has assigned to the end of life theme was designated, in our college. Therefore, student generally feels inadequately prepared by their pre-clinical training and teachings with regard to end of life issues. Thus, at this stage they developed conflict between the anticipated circumstances and the reality when their first patient died, actually. Due to lack of debriefing sessions many 
participants of this study, felt inadequately supported. Subsequently, young deaths, are perceived as tragedies by everyone especially medical students, as shown by a cross-sectional study done by Jessica Plante, at Quebec (Canada), in 2011'13. Moreover, the majority of students experienced sadness, frustration, guilt, selfdoubt, blame, helplessness and sense of failure. They felt that they have not done much to alleviate the pain of patient and his family. This leads to physician agony, disengagement, weariness and poor verdict as shown by the study of Dr Meier, at Mount Sinai medical school, New-York in $2001^{14}$.

Interestingly, diverse attitudes has been observed in the students who have uncertainty and ambiguity about the end of life event, in my study. For instance, some have strong responses, few have analytical one, whereas, some think about whether their response was the right one to have. Hence, medical education should encompass all aspects of end of life care from physical to the psychosocial and spiritual level, emphasized by the study of Dr Kvale at US in 199915 . Hence, a consistent mentor should available to the students all the times, especially, during uncertainty period. Whereas, formal guidelines for debriefing session should be set up in each medical colleges for the clinicians who participate in debriefing sessions. Since, there is no culture of formal debriefing session in our undergraduate medical curriculum, so, this sharing could be challenging. Due to time constrains, mostly students did not have a chance to debriefing sessions with supervisor/ teacher. As evidenced by, Dr Rode's in 2005, after his study at Northeastern medical schools, US. That an exclusive chance of teaching about death and coping with stress is often lost due to lack of emotional support to the participants ${ }^{16}$. Because very few of medical students becoming doctors knows about dying or death. Therefore, dealing with dying patients and patient's death should be integral part of health care education and training. Bristol University (UK, 2017) also supported, that formal education about 'end of life' must be integrated and implemented in to clinical practice $^{17}$. On the other hand, medical schools were slow to include meaningful end of life educational experience in their curricula, including mine. It reflected the medical culture that defines death as a 'failure', stated by Sullivan after a telephonic survey of US medical schools ${ }^{18}$.

Furthermore, most of our student believed that death of their patient could teach them to be better physicians, to be caring, to worry about quality of life rather than quantity of life. They confessed that how the deaths help them to flourish professionally. In general, students believed that care of dying could only be learnt by direct clinical experience as evidenced by the work of Dr Wear at Ohio University in $2003^{19}$. Evidence based end of life care, teaching \& training would be beneficial to health care workers including future doctors, as shown by the a study, conducted by Dr Brighton from UK in 201720. A former study in 2003 from US, by Dr Redinbaugh stated that, faculty development workshops would help supervisors to inculcate professionalism in novices ${ }^{21}$.

Bias \& conflict were controlled, as researcher has no influence on the researches. Reflexivity was controlled by using verbatim of participants for code and themes formation. Moreover, no Funding was provided by any source. Collection of data from a single medical college was the limitation of study. Data was audiotaped in native language, then transcribed in to English.

\section{CONCLUSION}

This research revolves around the theme, 'first death experience of the patient under care of a medical student.In essence, my study purposes a curricular model which includes, role modelling by the supervisors, debriefing sessions of students with supervisors and resident, following the incidence. Additionally, medical curricula should include reflective journaling; which encompass all the potential emotional impact of this demise. Likewise, introduction of faculty development programs; comprising training of supervisors and residents about sympathetic debriefing of their students. Consequently, it would be obliging to tackle the complexities which arise as a result of this tragic incident.

\section{CONFLICT OF INTEREST}

This study has no conflict of interest to be declared by any author.

\section{REFERENCES}

1. Mileder LP, Vajda C, Wegscheider T. Patient death in simulationbased medical education. Int J Med Educ 2015; 6: 109.

2. Collins A, McLachlan SA, Philip J. Initial perceptions of palliative care: an exploratory qualitative study of patients with advanced cancer and their family caregivers. Palliat Med 2017; 31(9): 82532.

3. Ratanawongsa N, Teherani A, Hauer KE. Third-year medical students' experiences with dying patients during the internal medicine clerkship: a qualitative study of the informal curriculum. Acad Med 2005; 80(7): 641-47.

4. Loos TM, Willetts GAP, Eileen Kempe A. A sudden death on clinical placement: A student's perspective of nurse grief. Contemp Nurse 2014; 47(1-2): 190-96. 
5. Williams CM, Wilson CC, Olsen $\mathrm{CH}$. Dying, death, and medical education: student voices. J Palliat Med 2005; 8(2): 372-81.

6. Marks SC, Bertman SL, Penney JC. Human anatomy: A foundation for education about death and dying in medicine. Clin Anat 1997; 10(2): 118-22.

7. Kelly E, Nisker J. Medical students' first clinical experiences of death. Med Educ 2010; 44(4): 421-28.

8. Creswell JW. Educational research: Planning, conducting, and evaluating quantitative. Prentice Hall Upper Saddle River, NJ; 2002.

9. Etikan I, Musa SA, Alkassim RS. Comparison of convenience sampling and purposive sampling. Am J Theor Appl Stat 2016; 5(1): $1-4$.

10. Biswas A, Dalal K, Abdullah ASM, Rahman AKMF, Halim A. Gestational diabetes: exploring the perceptions, practices and barriers of the community and healthcare providers in rural Bangladesh: a qualitative study. Metab Synd Obes 2020; 13: 1339.

11. Castleberry A, Nolen A. Thematic analysis of qualitative research data: Is it as easy as it sounds? Curr Pharm Teach Learn 2018; 10(6): 807-15.

12. Wald HS, Reis SP, Monroe AD, Borkan JM. 'The Loss of My Elderly Patient:'Interactive reflective writing to support medical students' rites of passage. Med Teach 2010; 32(4): e178-84.

13. Plante J, Cyr C. Health care professionals' grief after the death of a child. Paediatr Child Health. 2011; 16(4): 213-16.
14. Meier DE, Back AL. The inner life of physicians and care of the seriously ill. J Am Med Assoc 2001; 286(23): 3007-14.

15. Kvale J, Berg L, Groff JY, Lange G. Factors associated with residents' attitudes toward dying patients. Fam Med 1999; 31(10): 691-96.

16. Rhodes-Kropf J, Carmody SS, Seltzer D, Redinbaugh E, Gadmer $\mathrm{N}$, Block SD, et al. This is just too awful; I just can't believe I experienced that...": Medical Students' Reactions to Their "Most Memorable" Patient Death. Acad Med 2005; 80(7): 634-40.

17. Selman LE, Brighton LJ, Robinson V, George R, Khan SA, Burman R, et al. Primary care physicians' educational needs and learning preferences in end of life care: a focus group study in the UK. BMC Palliat Care 2017; 16(1): 17.

18. Sullivan AM, Lakoma MD. The status of medical education in end-of-life care. J Gen Intern Med 2003; 18(9): 685-95.

19. Wear D. "Face-to-face with it": medical students' narratives about their end-of-life education. Acad Med 2002; 77(4): 271-77.

20. Brighton LJ, Koffman J, Robinson V, Khan SA, George R, Burman $R$, et al. End of life could be on any ward really: A qualitative study of hospital volunteers' end-of-life care training needs and learning preferences. Palliat Med 2017; 31(9): 842-52.

21. Redinbaugh EM, Sullivan AM, Block SD, Gadmer NM, Lakoma M, Mitchell AM, et al. Doctors' emotional reactions to recent death of a patient: cross sectional study of hospital doctors. $\mathrm{Br}$ Med J 2003; 327(7408): 185. 